\title{
EFFECTS OF ANION ON THE CORROSION BEHAVIORS OF CARBON STEEL UNDER ARTIFICIAL RAIN FALL TEST
}

\author{
Dara TO $^{1}$, Tadashi Shinohara ${ }^{2}$, Osamu Umezawa ${ }^{3}$ \\ ${ }^{1}$ Material Reliability Unit, National Institute for Material Science (NIMS), Tsukuba 305-0047, JAPAN, \& Graduate \\ School of Engineering, Yokohama National University (YNU), Yokohama 240-8501, JAPAN \\ ${ }^{2}$ Material Reliability Unit, National Institute for Material Science (NIMS), Tsukuba 305-0047, JAPAN \\ ${ }^{3}$ Graduate School of Engineering, Yokohama National University (YNU), Yokohama 240-8501, JAPAN
}

\begin{abstract}
Rain is one of the main importance issues for atmospheric corrosion problem. Effects of rainfall on corrosion behaviors of carbon steels were investigated using artificial rainfall equipment. Three types of Atmospheric Corrosion Monitoring (ACM) sensors, which consist of Fe-Ag, Zn-Ag, and Al-Ag galvanic couples, were used to illustrate the correlation between the sensors output, Corrosion Rate (CR), and chemical concentration in the rain. The effects of ionic species on the corrosion behaviors were observed by using $\mathrm{NaCl}, \mathrm{KCl}, \mathrm{Na}_{2} \mathrm{SO}_{4}, \mathrm{NaNO}_{3}$, and $\mathrm{KNO}_{3}$ as rainfall solutions. The result revealed that the rainfall rate was insensitive to ACM sensors outputs and CRs. In contrast, the chemical species and their concentrations in the rainfall solution significantly affected the ACM outputs and CRs. The corrosivity of the cations $\left(\mathrm{Na}^{+}\right.$and $\left.\mathrm{K}^{+}\right)$is negligible compared to the anions $\left(\mathrm{Cl}, \mathrm{SO}_{4}^{2-}, \mathrm{NO}_{3}^{-}\right)$.For a given number of molar concentration, the CRs resulted from the corrosivity of $\mathrm{SO}_{4}^{-2}$ anions were higher than that of $\mathrm{Cl}$ and $\mathrm{NO}_{3}{ }^{-}$anions, respectively. According to the empirical data, the CRs is increased and then reach a steady state as the molar concentration is continuously increased. This research also indicates that the ACM sensors outputs of Fe-Ag and ZnAg couples are capable of estimating corrosivity of the atmosphere, while the ACM sensor of Al-Agcouple can be used to determine not only the time of wetness but also the typeofchemical species in the environment. The research methods discussed in this paper proves that the CRs are dependent on the atmospheric composition and can be forecasted through ACM sensors.
\end{abstract}

Keywords: Corrosion Rate (CR), Atmospheric Corrosion, Air Pollution, Atmospheric Corrosion Monitoring (ACM) Sensor, Sodium Chloride ( $\mathrm{NaCl}$ ), Sodium Sulfate $\left(\mathrm{Na}_{2} \mathrm{SO}_{4}\right)$, Sodium Nitrate (NaNO$)_{3}$, Potassium Chloride ( $\mathrm{KCl}$ ), Potassium Nitrate $\left(\mathrm{KNO}_{3}\right)$.

\section{INTRODUCTION}

An environmental effect, such as corrosion attack, is the most important factor for the design of metallic structure like infrastructures, automotive, and other equipment, which usually exposed to an outdoor environment. Atmospheric corrosion is a very complicated process that causes deterioration of metallic materials by chemical or electrochemical reaction between the metal and its environment. The Relative Humidity $(\mathrm{RH})$, time of wetness and numerous pollutant substances which involve species deposited from atmosphere and species from the metal resulting from corrosion itself affect to the atmospheric corrosion [1].The atmospheric corrosions are often classified into several qualitative zones, based on subjective assessments of pollution factors, namely Rural, Urban, Industrial, and Marine atmosphere [1-6]. Generally, therural area is low corrosivity while Urban, Industrial, and Marine atmosphere are, respectively, higher corrosivity due to the existence of higher chemical contain in the atmosphere $[3,4]$. The corrosive of marine area relates to the existence of high $\mathrm{Cl}^{-}$concentrations in the atmosphere. Other chemical species that can be found in the Urban and Industrial atmospheres are $\mathrm{SO}_{2}, \mathrm{CO}_{2}$, and $\mathrm{NO}_{2}$, that product by gas emission from the combustion engine [6-8]. Further oxidation of $\mathrm{SO}_{2}$, usually in the presence of a catalyst such as $\mathrm{NO}_{2}$, forms $\mathrm{H}_{2} \mathrm{SO}_{4}$, and thus, acid rain could initiate [8].

Atmospheric corrosion, depends mainly on air pollution, is commonly initiates and develops under the thin water films, the film which is considered as surface electrolyte layer, formed by fog, dew, or raindrop. For a given time of wetness (time during which the wet film exists), the greater the pollution value, the greater the corrosivity formation. To know and elucidate the effect of the pollution on the corrosion behaviors, it is necessary to identify the pollutant substances, and likewise, the time of wetness should be taken into account. In this research, the corrosion behaviors of carbon steel affected by several types of ionic species were investigated by simulating artificial rainfall test. Three type of ACM sensors were used to create the empirical data for estimating the relation between sensor outputs and CRs. The chemical species and its concentration in the rainfall solution were taken as the main parameters of corrosion.

\section{EXPERIMENTAL PROCEDURE}

\subsection{Chemical Composition in Rainfall Solution}

Chemical properties, $\mathrm{pH}$ values, and electrical conductivities of actual rain at National Institute for Material Science 
(NIMS), Tsukuba, Japan, were analyzed. The measurement results show that the highest chemical concentration is $\mathrm{HCO}_{3}^{-}$and follow by $\mathrm{NO}_{3}^{-}, \mathrm{SO}_{4}^{-}$, and $\mathrm{Cl}^{-}$(as seen in Table (1)). The $\mathrm{pH}$ value and electrical conductivities are about 4.8 $\sim 5.7$ and $10 \sim 43 \mu \mathrm{s} / \mathrm{cm}$ respectively. In general, $\mathrm{SO}_{4}{ }^{-}, \mathrm{Cl}^{-}$, and $\mathrm{NO}_{3}{ }^{-}$are the most aggressive ionic species for corrosion acceleration $[1,2]$. In this experiment, $\mathrm{NaCl}, \mathrm{KCl}, \mathrm{Na}_{2} \mathrm{SO}_{4}$, $\mathrm{NaNO} 3$, and $\mathrm{KNO}_{3}$ species, which are the major contain in the actual rain, were mixed with Deionized water and used as artificial rainfall solution.

\subsection{Artificial Rainfall Equipment}

The artificial rainfall equipment, as seen in Fig. 1, composed of a chamber, a water reservoir, an air-compressor-mixer, ACM sensors which are connected to a Data logger, and a nozzle spray which is installed on the top of the chamber. The rainfall distribution is considerably uniform, and it can be adjusted to get a wide range of rainfall rate: $0.5 \mathrm{~mm} / \mathrm{h}$ to $10 \mathrm{~mm} / \mathrm{h}$. However, the results of this experiment show that the rainfall rate, $\mathrm{H}(\mathrm{mm} / \mathrm{h})$, is insensitive to the CRs and ACM sensors outputs. Hence, $\mathrm{H}=1 \mathrm{~mm} / \mathrm{h}$ was used for all cases.

Table-1: Chemical properties in actual rainwater [9]

\begin{tabular}{|c|c|c|c|c|}
\hline \multirow{2}{*}{ Date } & \multirow{2}{*}{ 06-Jun } & \multirow{2}{*}{ 07-Jul } & \multicolumn{2}{|l|}{ 25-Jul } \\
\hline & & & Beginning & Main \\
\hline $\mathrm{pH}(24 \mathrm{C})$ & 5.5 & 4.8 & 5.2 & 5.7 \\
\hline $\begin{array}{l}\text { Conductivity } \\
(\mu \mathrm{s} / \mathrm{cm})\end{array}$ & 10 & 26 & 43 & 11 \\
\hline \multicolumn{5}{|c|}{ Concentration (mg/L) } \\
\hline $\mathrm{Cl}^{-}$ & 0.7 & 0.6 & 2.4 & 0.7 \\
\hline $\mathrm{SO}_{4}{ }^{2-}$ & 2.0 & 3.7 & 5.3 & 1.3 \\
\hline $\mathrm{NO}_{3}^{-}$ & 1.2 & 3.5 & 7.5 & 1.4 \\
\hline $\mathrm{Na}^{+}$ & 0.3 & 0.5 & 2.0 & 0.4 \\
\hline $\mathrm{K}^{+}$ & 0.3 & 0.7 & 2.3 & 0.7 \\
\hline $\mathrm{Ca}^{2+}$ & $<0.1$ & 0.2 & 0.2 & $<0.1$ \\
\hline $\mathrm{Mg}^{2+}$ & $<0.1$ & $<0.1$ & $<0.1$ & $<0.1$ \\
\hline $\mathrm{HCO}_{3}^{-}$ & $<5.0$ & $<5.0$ & $<5.0$ & $<5.0$ \\
\hline
\end{tabular}

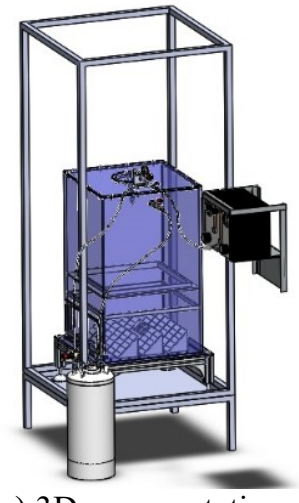

(a) $3 \mathrm{D}$ representation

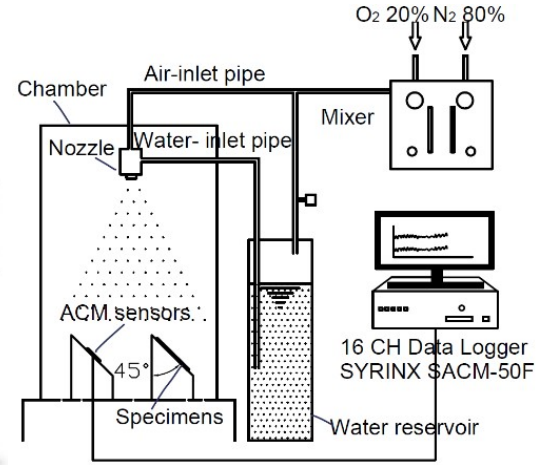

(b) Schematic illustration
Fig-1: Artificial rainfall equipment

\subsection{Atmospheric Corrosion Monitoring (ACM)}

\section{Sensor}

It has been known that galvanic couple sensing probe was used for dew detector [10] time-of-wetness meter [11], or moisture sensor [12]. Further integrations and applications of this type of sensor, which is called Atmospheric Corrosion Monitoring (ACM) sensor, has been used to predict the behaviors of corrosion under atmospheric condition [13]. The schematic illustration of ACM sensor, which consists of the Fe-Ag couple, is presented in the Fig. 2. The signal output, which can be called galvanic current, range between nanoampere to milliampere, depends mainly on the electrical conductivity of aqueous film formed by dew or raindrop on the striped surface of the sensor, as seen in Fig. 2 (b). And the signal outputs of the sensors are recorded and collected every minute by $16 \mathrm{CH}$ Data logger SYRINX SAXM-50F. In this research, three types ACM sensors, $\mathrm{Fe}-\mathrm{Ag}, \mathrm{Zn}-\mathrm{Ag}$, and $\mathrm{Al}-\mathrm{Ag}$, were used to investigate the phenomenon of corrosion through the signal output of ACM censors.

\subsection{Exposure Test and Measurement}

Low-carbon steel sheets, SPCC, were used as specimens and exposed to the artificial rainfall by a limited and single face. The backside, cut edge, and fringe of the specimens were covered by polyethylene sheetin order to avoid undesired corrosion occurs, as seen in Fig. 3. The ACM sensors and specimens were installed at the bottom of the chamber and incline $45^{\circ}$ with a vertical plan. Each test was conducted 16 hours with two times repeated. The CRs were computed based on weight loss method; the samples were immersed in the Hydrochloric Acid $(\mathrm{HCl})$ to remove the corrosion products or rust layer, then weight-loss was measured (ISO/DIS 8403.3 [14]).

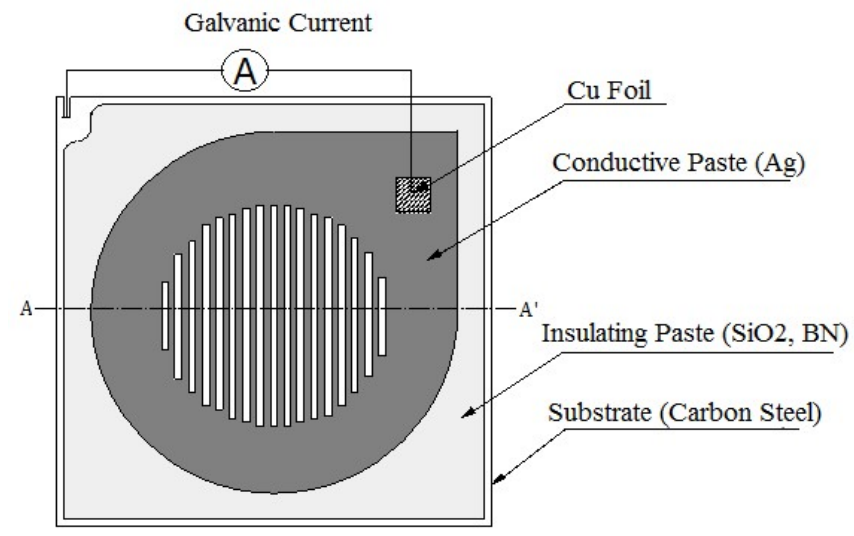

(a)

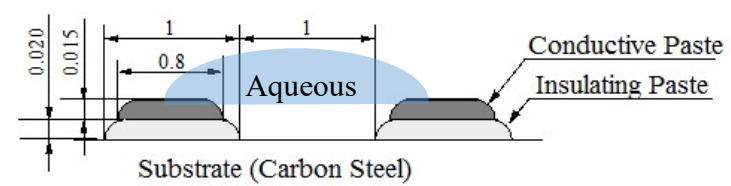

(b)

Fig-2: Schematic illustration of Fe-Ag ACM sensor, (a) overall view, (b) section view [13]. 


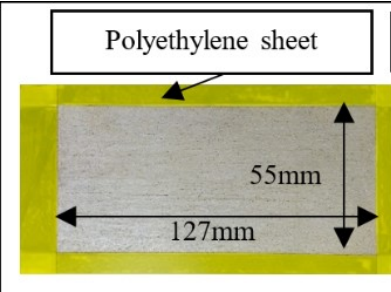

(a)

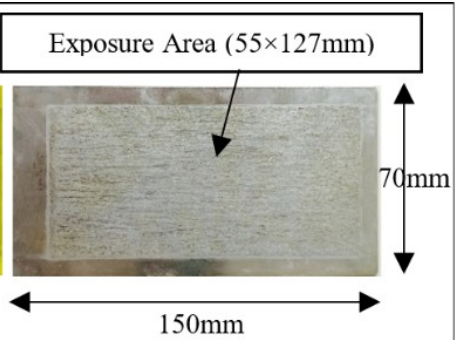

(b)
Fig-3: Carbon steel sheet specimens, (a) Preparation the specimen before exposure test, (b) After removing corrosion product.

\section{RESULTS}

\subsection{Molarity and Electrical Conductivity}

The electric conductivity, $\sigma(\mu \mathrm{s} / \mathrm{cm})$, of all solutions linearly increase with the increasing of molarity, c (mol/L), (Fig. 4). In addition, $\mathrm{Na}_{2} \mathrm{SO}_{4}$ solutions present the highest electrical conductivity while $\mathrm{NaCl}$ and $\mathrm{NaNO}_{3}$ solutions are considerably similar trend line. It should be noted that the relation between $\sigma$ and $\mathrm{c}$ follow a general formula:

$\sigma=\beta . c+D$

Where $\beta$ is the electricity coefficient and $\mathrm{D}$ is electrical conductivity of deionize-water, in this experiment $\mathrm{D} \approx 0.9$ to $1.5 \mu \mathrm{s} / \mathrm{cm}$.

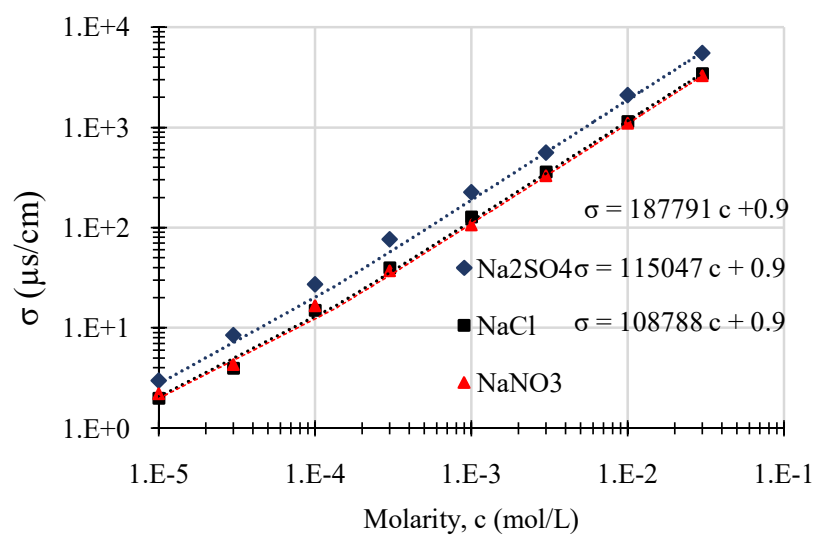

Fig-4: The eclectically conductivity of $\mathrm{Na}_{2} \mathrm{SO}_{4}, \mathrm{NaCl}$, and $\mathrm{NaNO}_{3}$ solutions in function of molar concentration

\subsection{Corrosion Rate Calculation}

After removing corrosion product, or rust layer, from the surface of the samples, weight loss was measured and converted to thickness loss. The thickness loss per year is called Corrosion Rate, CR ( $\mathrm{mm} / \mathrm{y})$. The CR of the exposure sample can be calculated according to the following equation:

$$
\mathrm{CR}(\mathrm{mm} / \mathrm{y})=\frac{10 \mathrm{w}_{\mathrm{y}}}{\rho \mathrm{A}}
$$

Where $\mathrm{W}_{\mathrm{y}}$ is weight loss per year $(\mathrm{g} / \mathrm{y}), \rho$ is the density of carbon steel $\left(7.86 \mathrm{~g} / \mathrm{cm}^{3}\right)$, and $\mathrm{A}$ is the exposed area $\left(12.7 \times 5.5 \mathrm{~cm}^{2}\right)$.

\subsection{Effect of Rainfall Rate}

The rainfall rates were insensitive to $\mathrm{CRs}$ and $\mathrm{ACM}$ sensors outputs as seen in Fig. 5. It can be explained by the fact that the CR can approach maximum when the electrolytesurface film covering the metal become very thin, below $56 \mu \mathrm{m}$ $[1,9,15-17]$. For the larger thickness of the film, especially under the rainfall with homogenous concentration, the CRs will stabilize at a constant value.

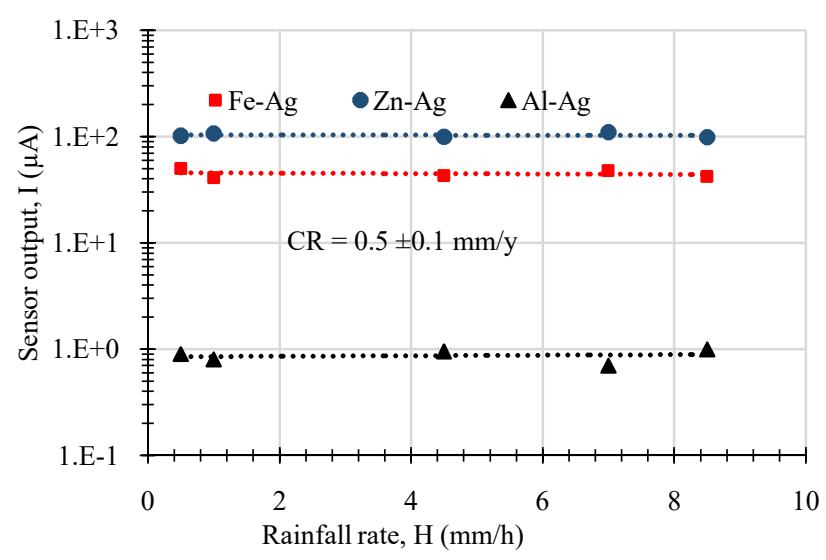

Fig -5: The effect of rainfall rate to the sensor output in $\mathrm{Na}_{2} \mathrm{SO}_{4}$ solution with the concentration of $3 \times 10^{-4} \mathrm{~mol} / \mathrm{L}$

\subsection{Effect of Anions on Corrosion Rate}

In water, $\mathrm{NaCl}$ for instance, the molecules will separate into ions: $\mathrm{Na}^{+}$(cation), and $\mathrm{Cl}^{-}$(anion). And likewise for $\mathrm{KCl}$, $\mathrm{NaNO}_{3}$, and $\mathrm{KNO}_{3}: \mathrm{K}^{+}, \mathrm{Cl}^{-}, \mathrm{Na}^{+}, \mathrm{NO}_{3}{ }^{-}$. The negative charge, called anion, is the most corrosive ion because it has much more tendency to catch electron from the metal surface. Consequently, the metal will oxidize by transferring the electron to the anion and liberating metal ion from metal the surface. Fig. 6 show CRs resulting from the effect of the anion and the variation of molarity. Evidently, Fig. 6 (a) and (b)indicate corrosion tendency depend on $\mathrm{Cl}^{-}$and $\mathrm{NO}_{3}^{-}$ respectively, while the effect of $\mathrm{K}^{+}$and $\mathrm{Na}^{+}$is negligible. This Phenomenondoes not mean for all cation, especially $\mathrm{H}^{+}$ that has natural tendency to accept the electron from metallic-solution interface.

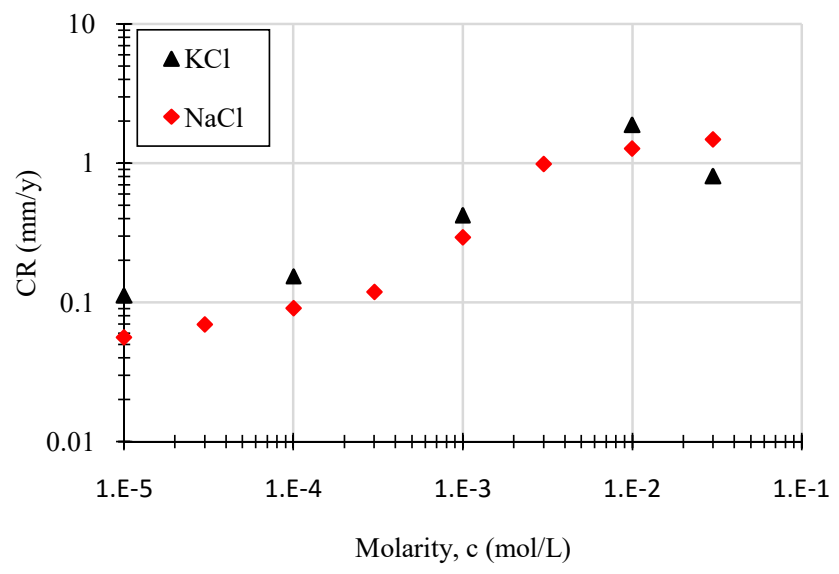

(a) 


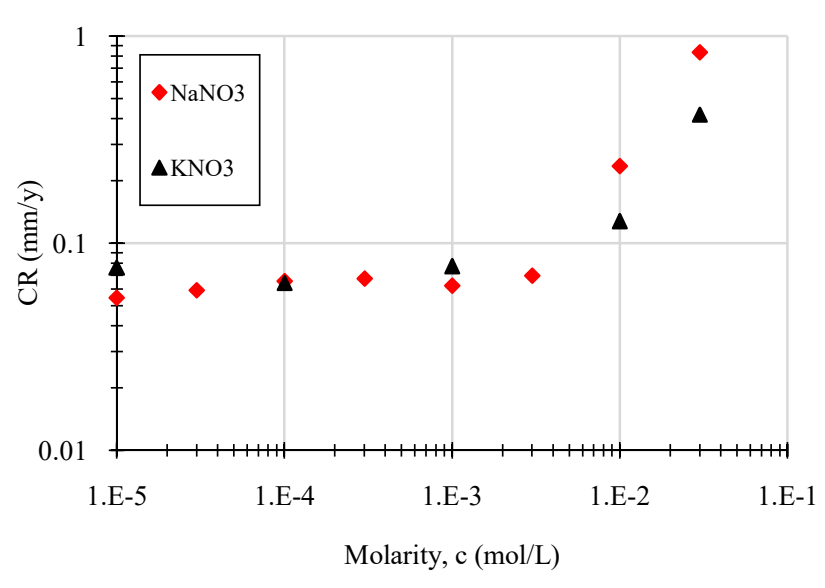

(b)

Fig-6: Effect of anion on corrosion rate, (a) the effect of $\mathrm{Cl}^{-}$ ,(b) the effect of $\mathrm{NO}_{3}{ }^{-}$

\subsection{Relation between Corrosion Rate and Molarity}

Fig. 7 shows the logarithmic scale representation of CR in function of molar concentration. Each data point is the CR mean value of two-time repeated tests with three samples. As it can be seen, $\mathrm{SO}_{4}{ }^{2-}$ is the most aggressiveness anion, and follow by $\mathrm{Cl}^{-}$and $\mathrm{NO}_{3}{ }^{-}$, respectively. According to the empirical data, the $\mathrm{CR}$ of $\mathrm{Na}_{2} \mathrm{SO}_{4}$ and $\mathrm{NaCl}$ indicate the transition from corrosion acceleration to deceleration and tend to reach a steady state when molarity is continuously increased. In particular, the $\mathrm{CR}$ of $\mathrm{NaNO}_{3}$ is considerably constant, $\mathrm{CR} \approx 0.05 \mathrm{~mm} / \mathrm{y}$, for $\mathrm{c}<3.10^{-3} \mathrm{~mol} / \mathrm{L}$, elsewhere, c $>3.10^{-3}$, the $\mathrm{CR}$ rapidly raises up. For the smaller concentration, c $<3.10^{-5} \mathrm{~mol} / \mathrm{L}$, all the $\mathrm{CRs}$ are approximately similar and remain steady.

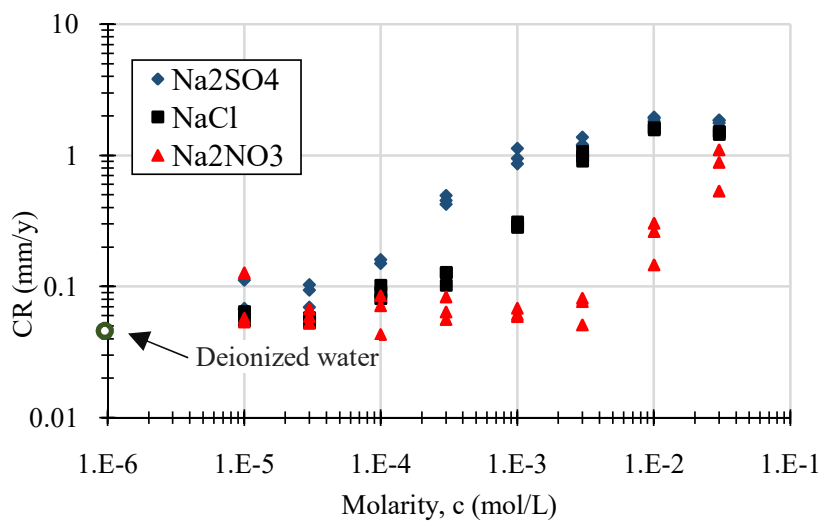

Fig-7: Corrosivity of carbon steel sheet corroded by $\mathrm{Na}_{2} \mathrm{SO}_{4}, \mathrm{NaCl}$, and $\mathrm{NaNO}_{3}$ solutions

\subsection{Relation between Sensor Outputs and Molar}

\section{Concentration}

Fig. 8 shows the relation between sensor outputs in function of molar concentrations. The galvanic currents of the three sensors increase with the increasing of molar concentrations, except Al-Ag galvanic current in $\mathrm{NaNO}_{3}$ solution (see Fig 8 (c)) that considerably unchangeable when $c>10^{-4} \mathrm{~mol} / \mathrm{L}$. For
$\mathrm{Fe}-\mathrm{Ag}$ and $\mathrm{Zn}-\mathrm{Ag}$ sensor, the galvanic currents in the $\mathrm{Na}_{2} \mathrm{SO}_{4}$ solutions are higher than those in $\mathrm{NaCl}$ and $\mathrm{NaNO}_{3}$ solutions, respectively (see Fig. 8 (a) and (b)). On the contrary, the Al-Ag galvanic currents in $\mathrm{Na}_{2} \mathrm{SO}_{4}$ solutions are lower than those in $\mathrm{NaNO}_{3}$ and $\mathrm{NaCl}$ solution (see Fig. 8 (c)).

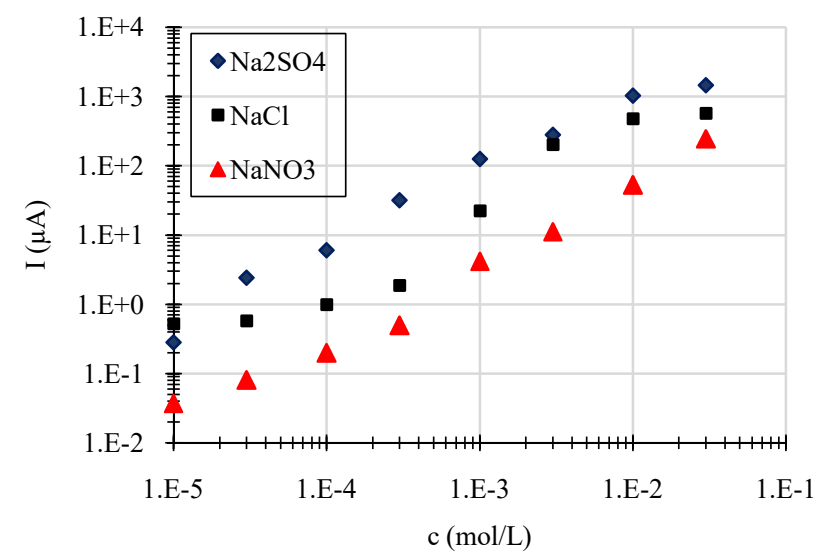

(a)

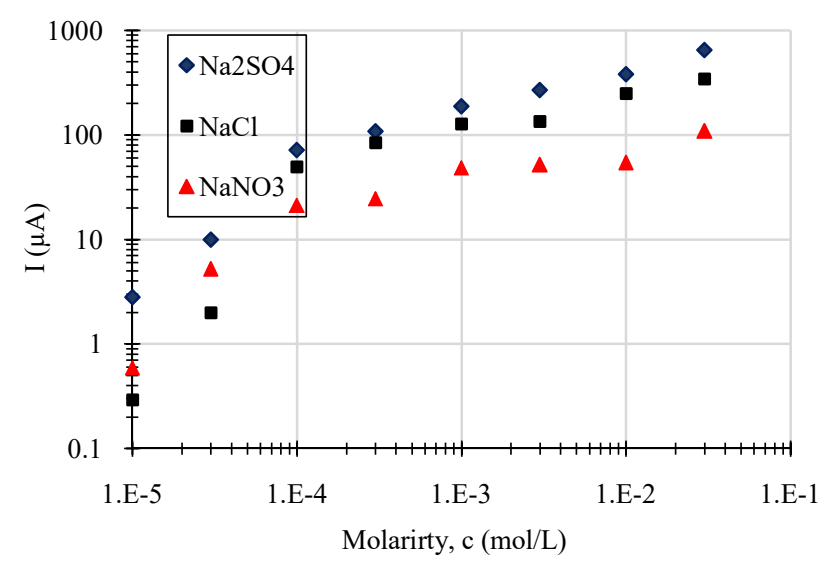

(b)

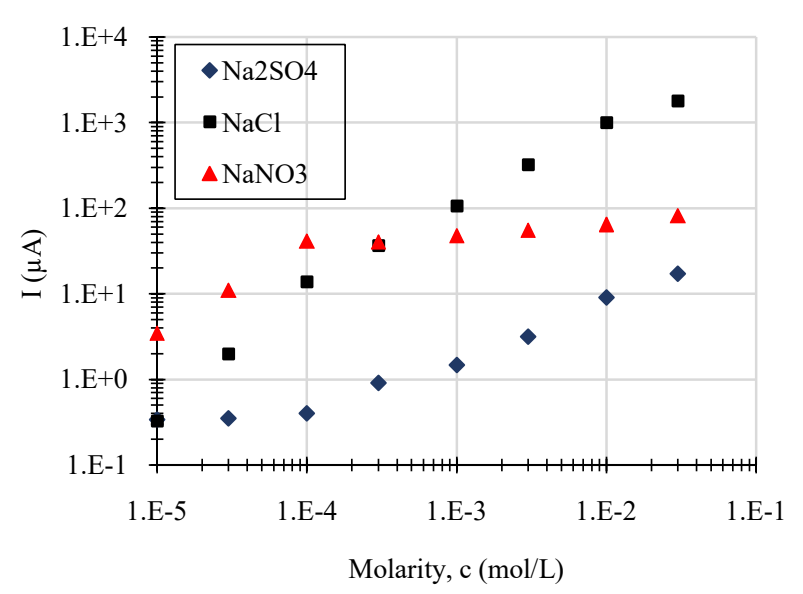

(c)

Fig-8: Relation between molar concentration and sensor outputs, (a) Fe-Ag galvanic couple, (b) Zn-Ag Galvanic couple, and (c) Al-Ag galvanic couple. 


\subsection{Relation between CR and Sensor Output}

Recall that; the sensor output is a current of the galvanic couple that highly depend on ionic species in the aqueous film formed on the surface of ACM sensor. Fig. 9 (a), (b), and (c) present the outputs of the three sensors, Fe-Ag, Zn$\mathrm{Ag}$, and $\mathrm{Al}-\mathrm{Ag}$ in function of CR. With $\mathrm{Na}_{2} \mathrm{SO}_{4}, \mathrm{NaCl}$, and $\mathrm{NaNO}_{3}$ solutions, the sensor outputs of Fe-Ag and $\mathrm{Zn}-\mathrm{Ag}$ couple are relatively similar and congregated as a curve, as seen in Fig. 9 (a) and (b). Conversely, the outputs of Al-Ag sensor are completely deviated by chemical species (Fig. 9 (c)). Additionally, $\mathrm{Na}_{2} \mathrm{SO}_{4}$ solution is less sensitive to the Al$\mathrm{Ag}$ sensor output, while it is sensible to the Fe-Ag and $\mathrm{Zn}$ Ag.

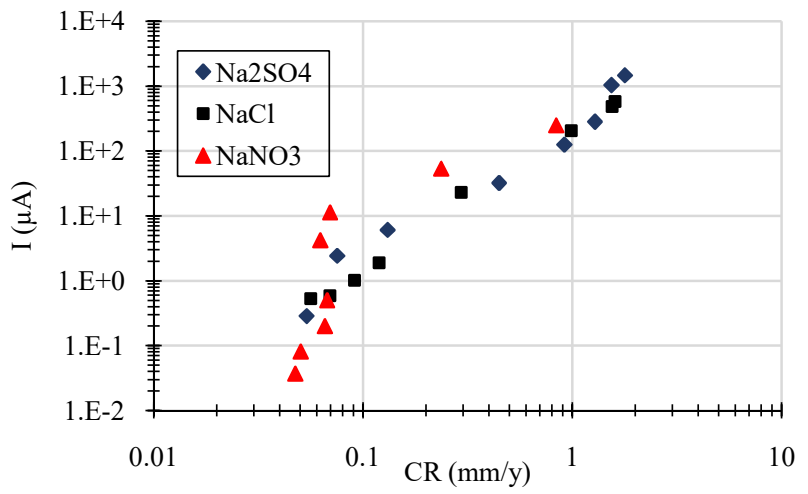

(a)

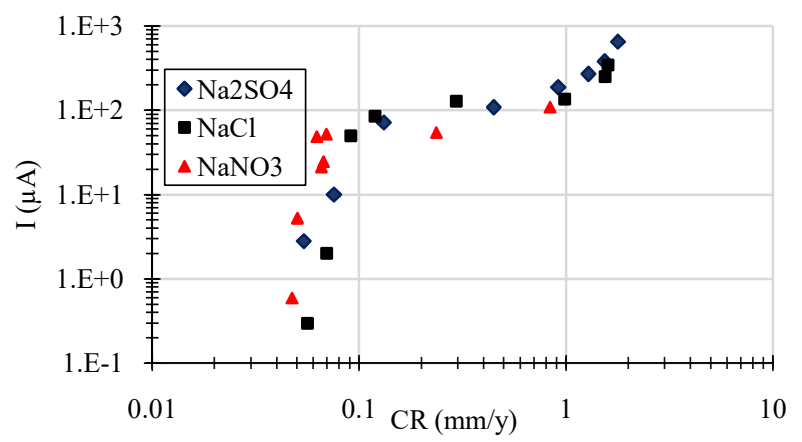

(b)

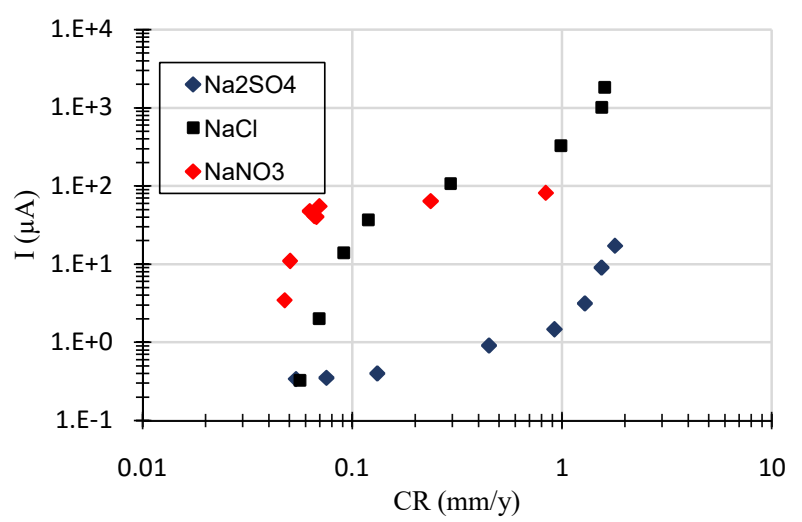

(c)

Fig -9: Relation between sensor output and CR, (a) Fe-Ag, (b) $\mathrm{Zn}-\mathrm{Ag}$, and (c) Al-Ag galvanic couple

\section{DISCUSSION}

Atmospheric corrosion is an electrochemical process which can only proceed in the presence of an electrolyte film. It is, therefore, to be considered as discontinuous process, where the total corrosion loss, COR, in a given time or period is determined by the time of wetness, $t_{\mathrm{wn}}$, and the average of corrosion rate, $\mathrm{CR}$, during the each period, $\mathrm{n}$, of condensation[1]:

$\operatorname{COR}=\sum_{\mathrm{n}} \mathrm{t}_{\mathrm{wn}} \cdot \mathrm{CR}_{\mathrm{n}}$

The calculation the time of wetness based on meteorological data (by taking $\mathrm{RH} \geq 80 \%$ and $\mathrm{T} \geq 0{ }^{0} \mathrm{C}$ ) might not achieve the exact time that makes corrosion possible. Thus, the technical measurement method using ACM sensor exposure to the actual environment is more preferable. Virtually, Fe$\mathrm{Ag}$ and/or $\mathrm{Zn}-\mathrm{Ag}$ galvanic couples enable to estimate the time of wetness, $t_{w n}$, and corrosion rate, $C_{n}$, through the empirical data (see Fig. 9 (a) and (b)). Al-Ag couple, however, is unable to forecast the $\mathrm{CR}$ in the unknown pollution species, especially the mixed species in the atmosphere, due to the inconsistent relation of I-CR in different solutions (Fig 9 (c)). Nonetheless, the Al-Ag enables to estimate the time of wetness based on the great lifetime service. And also, it allowspredicting the chemical species in the environment. For instance, if the $\mathrm{CR}$ is high, and the $\mathrm{Al}-\mathrm{Ag}$ sensor output is low, the $\mathrm{SO}_{4}{ }^{2-}$ ions is assumed as the major contain in the solution or the environment. It has to be noted that the service-life of Fe-Ag galvanic sensor is much lower than those of $\mathrm{Zn}-\mathrm{Ag}$ and $\mathrm{Al}-$ $\mathrm{Ag}$, respectively. The rust layer could be visually detected on the striped surface of the Fe-Ag sensor after about 64 hours rain (see Fig. 10), and it results to the increasing of the sensor output and decreasing the sensibility of the sensor. Thus, it is recommended to change the sensor frequently during the exposure test.

\section{CONCLUSION}

The experimental analysis of the corrosion behaviors under the artificial rainfall investigation allows to conclude as below:

- The rainfall rates were insensitive to ACM sensors outputs and CRs. In contrast, the chemical species and their concentrations in the rainfall solution significantly affected the ACM outputs and the CRs.

- The corrosivity ofcations is negligible compared to anions. For a certain of molar concentration, the most aggressiveness ions are $\mathrm{SO}_{4}^{-}, \mathrm{Cl}^{-}$, and $\mathrm{NO}_{3}$, respectively.

- For further increasing molar concentration, the CR tends to reach a steady state at the maximum value of $\mathrm{CR}=2 \mathrm{~mm} / \mathrm{y}$.

- The ACM sensors are capable of estimating the time of wetness and aggressivity of atmosphere, and thus the total corrosion loss could be estimated.

- The lifetime of Fe-Ag galvanic sensor is much shorter than those of $\mathrm{Zn}-\mathrm{Ag}$, and $\mathrm{Al}-\mathrm{Ag}$ respectively since the rust layer visually appears after 64 hours rain; thus the sensibility of the sensor would not perform well. 


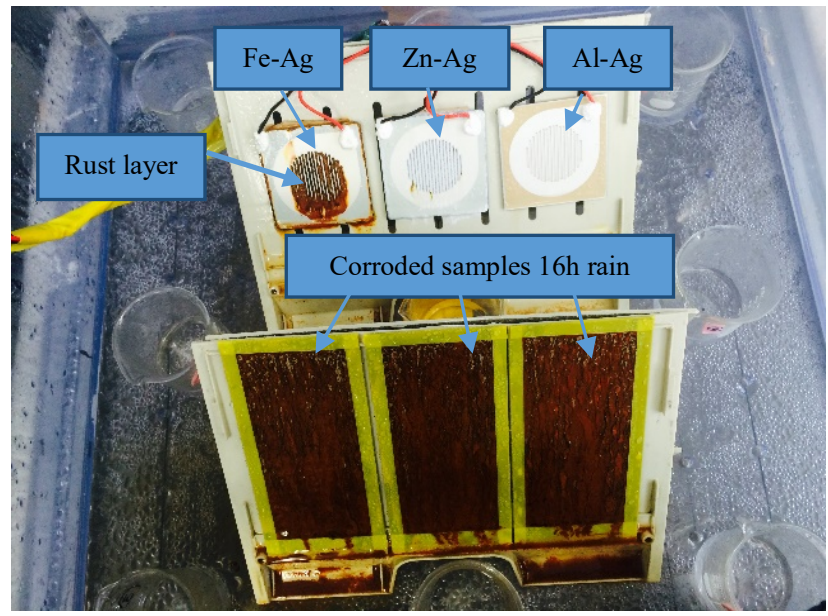

Fig-10: Overview of corroded sample after 16 hours rain with $\mathrm{NaCl} 10^{-2} \mathrm{~mol} / \mathrm{L}$, and ACM sensor after 80 hours rain

\section{REFERENCES}

[1] F. Mansfeld: Applied Sciences, 203(Electrochemical and Optical Techniques for the Study and Monitoring of Metallic Corrosion, 1991) pp. 571-584.

[2] ISO 9223: Corrosion of metals and alloys, Corrosivity of Atmospheres. Classification, (1992).

[3] D. de la Fuente, I. Díaz: Corrosion Science. 53 (2011) pp. 604-617

[4] M. Morcillo B. Chico: Corrosion Science. 77 (2013) pp. 6-24

[5] Sei J. Oha, D.C. Cookb: Corrosion Science 41 (1999) pp. 1687-1702

[6] J. Morales, S. Martin-Krijerz: Corrosion Science 47 (2005) pp. 2005-2019

[7] S. Sudalma, P. Purwanto: Procedia Environmental Sciences 23 ( 2015 ) pp. $247-252$

[8] Jekti Prihatin, A. Duran Corebima, Ariffin, Abdul Gofur, The effect of exposure of mulberry to acid rain on the defects Cocoon of Bombyxmori L, Procedia Environmental science 23 (2015) 186-191

[9] T. Shinohara: ISSN 0892-4228, Corrosion Engineering, 63 (2014) pp. 86-92.

[10] P.J. Sereda: ASTM Bulletin, No. 228, (1958) pp. 53: ibid., No.238. (1958) pp. 61; ibid., No. 246, (1960) pp. 47

[11] P.R. Grossman: "Atmospheric Factors Affecting Corrosion of Metals,“ Ed. By S.K Conburn, p. 5, ASTM STP 66 (1978).

[12] P.J. Sereda, S.G. Croll and H.F. Slade: "Atmospheric Corrosion of Metal," Ed. By S.W. Dean, Jr. and E.C Rhea, p. 267, ASTM STP 767 (1982).

[13] S.i. Motoda, Y. Suzuki, T. Shinohara: Corrosion Engineering. 43 (1994) pp. 583-594.

[14] ISO/DIS 8403.3: Metals and alloys. Procedures for removal of corrosion products from corrosion test specimens, 1985.

[15] M. Stratmann, H. Strecke: Corrosion Science. 30 (1990) pp. 715-734.

[16] A. Nishikata, Y. Ichihara: J. Electrochem. Soc. 144 (1997) pp. 1244-1252.

[17] T. Tsuru, A. Nishikata: Mater. Sci. Technol. A198 (1995) 161-168. 